\title{
Chapter 10 \\ Rapid Flood Mapping Using \\ Multi-temporal SAR Images: \\ An Example from Bangladesh
}

\author{
Kabir Uddin, Mir A. Matin, and Rajesh Bahadur Thapa
}

\subsection{Introduction}

In the $\mathrm{HKH}$ region, large areas in Afghanistan, Bangladesh, China, India, Myanmar, Nepal, and Pakistan get inundated by floodwater during every rainy season. Among them, Bangladesh has been experiencing record-high floods where four types prevail: flash flood, local rainfall flood, monsoon river flood, and storm-surge flood; and these occur almost every year due to Bangladesh's unique geographical setting as the most downstream country in the HKH region (Ozaki 2016; FFWC 2020). On an average, about $26,000 \mathrm{~km}^{2}$ of Bangladesh is inundated during the monsoon season (Fig. 10.1). Among all the disaster years, the floods of 1988 were the most catastrophic when more than 2379 people were killed, 45 million were affected, and $82,000 \mathrm{~km}^{2}$ of land was inundated (Dewan 2015; Rasid and Pramanik 1993).

For the mitigation of flood disaster impacts, it is very critical to know which areas are inundated and which are not. Based on timely information on inundation, disaster and relief agencies can speed up emergency response for relief and rescue measures. At the same time, the flood-affected people can also find safe shelters (Manjusree et al. 2012; Uddin et al. 2013). Therefore, flood early warning, near real-time (NRT) inundation information and preparedness are the best options in flood disaster management (Uddin et al. 2019). Flood maps provide essential inputs toward assessing the progression of inundation area and the severity of the flood situation (Amarnath and Rajah 2016; Cigna and Xie 2020). Satellite-based Earth observation (EO) techniques are used for preparing such flood maps that help in assessing damages to residential property, infrastructure, and crops (Hill 2016; Uddin and Shrestha 2011).

K. Uddin $(\bowtie) \cdot$ M. A. Matin $\cdot$ R. B. Thapa International Centre for Integrated Mountain Development, Kathmandu, Nepal e-mail: kabir.uddin@icimod.org

B. Bajracharya et al. (eds.), Earth Observation Science and Applications for Risk Reduction and Enhanced Resilience in Hindu Kush Himalaya Region, https://doi.org/10.1007/978-3-030-73569-2_10 


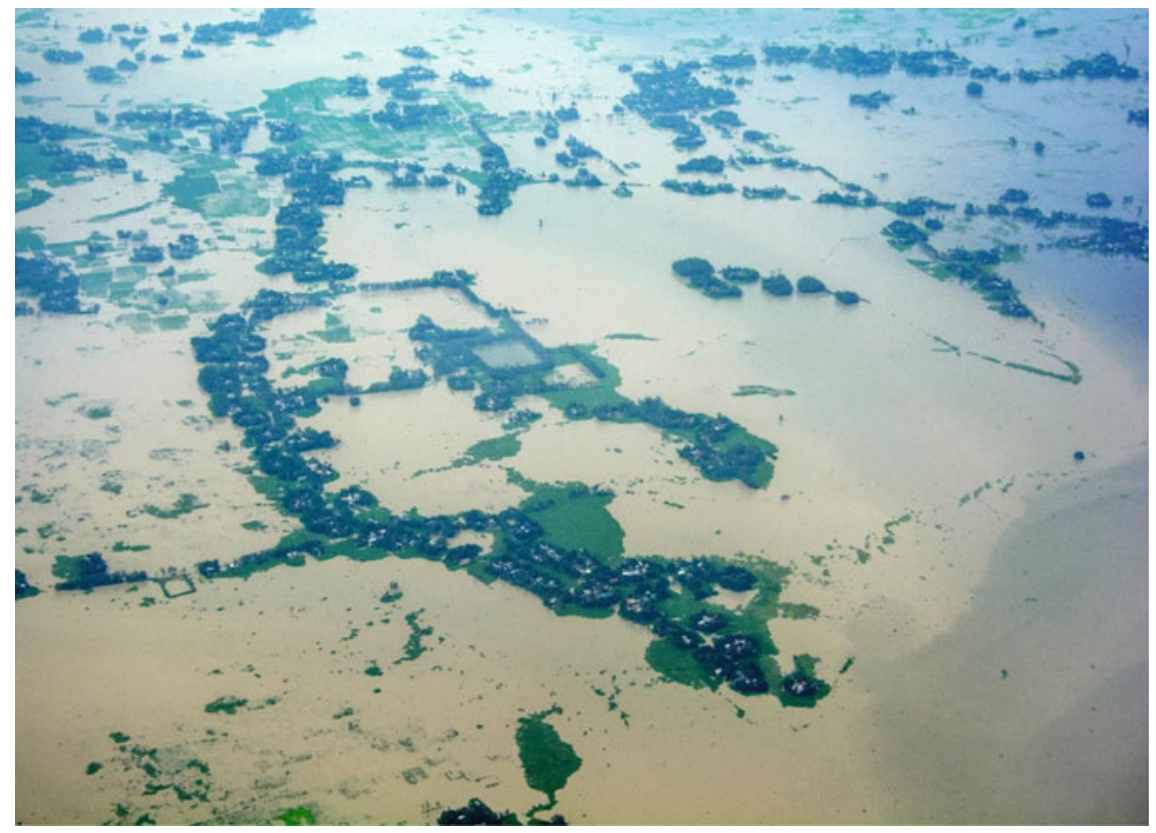

Fig. 10.1 Inundation photo (August, 18 2017, Sirajganj) taken from an airplane; the gray water reflects the inundated areas, and the green patches are rural settlements covered by floodwater. Photo by Kabir Uddin

ICIMOD developed a rapid flood mapping method when Bangladesh was hit by floods in 2017 (Uddin et al. 2019). The flood maps were prepared for the months of March, April, June, and August and were provided to the disaster management agencies in order to prioritize relief and rescue operations. With some refinements, same method was used for mapping the floods of 2018 and 2019 in Bangladesh, Nepal's Terai, and the Koshi River Basin in order to support flood management and relief measures. This chapter explains the rapid flood mapping methodology developed for the 2019 floods in Bangladesh and its application.

\subsection{Satellite Data in Flood Mapping}

Though optical satellite imagery is most applicable for landform mapping, nevertheless, it is not appropriate for flood mapping due to the persistent cloud cover during the flood time (Uddin et al. 2019). As compared to optical data, microwave, i.e., SAR data are often used for flood area mapping. SAR is an active sensor that transmits a signal and receives the backscatter of the surface features using its own energy, unlike the optical sensor's dependency on the sun's electromagnetic energy. The SAR system operates on a long wavelength and can penetrate cloud, rain 
showers, and fog, making monitoring possible during flooding. Furthermore, the inundated areas often remain calm making the water surface smooth which results in less signal returned to the satellite. As a result, the inundated areas in the radar image appear darker in contrast to other land areas. These characteristics of SAR add significant values in terms of determining flood extent mapping and accurate measurement of streams, lakes, and wetlands (Ajmar et al. 2017; Amarnath and Rajah 2016; Ohki et al. 2016; Voormansik et al. 2014). Currently, satellites like ALOS-2, RADARSAT-2, TerraSAR, and Sentinel-1 are in operation and providing globally consistent SAR data. These satellites operate in different bands of microwave wavelength: ALOS-2 in L; RADARSAT- 2 and Sentinel- 1 in C; and TerraSAR in $\mathrm{X}$. There are many flood mapping applications available from these satellites in the scientific literature, and it is suggested that compared to other bands, the L-band data provides the best results due to its longer wavelength and better penetration capability (Longépé et al. 2011; Shimada et al. 2014). However, ALOS-2, RADARSAT-2, and TerraSAR are operated on a commercial basis which involves procurement process that costs time and money. Therefore, Sentinel-1 SAR images are mostly preferred in flood mapping as it is available soon after the data acquisition, it is web-based open access and free for all and maintains relatively high-frequent observations.

So, for rapid flood mapping, we can take advantage of the Sentinel-1 data available in the public domain. The great asset of Sentinel-1 SAR images is that the data are freely available within a few hours of capture which helps to support NRT emergency responses.

\subsection{SAR Data Processing Tools}

There are many SAR data processing and analysis tools available in both open access-MapReady, Sentinel Application Platform (SNAP), Google Earth Engine (GEE), InSAR Scientific Computing Environment (ISCE), Generic InSAR Analysis Toolbox (GIAnt), Repeat Orbit Interferometry PACkage (ROI_PAC), Delft Institute of Earth Observation and Space Systems (DORIS), Generic Mapping Tools Synthetic Aperture Radar (GMTSAR), and PolSAR. In commercial modesGlobalSAR, SARscape, Photomod Radar, SARPROZ, PCI, and GAMMA. The commonly used SAR processing tools on the open-access platform are MapReady, SNAP, GEE, and PolSAR Pro. These tools consist of proper documentation and can easily be handled by even non-expert flood analyst. In the commercial domain, the GAMMA software tool is widely used due to its availability on both desktops as well as cloud-computing platforms. The software is also popular among the SAR user communities for its capability inaccurate terrain correction. However, the cost factor of such commercial tools may be an issue with some users.

As for cloud-based data processing platforms like GEE, they provide excellent opportunity to process a large volume of satellite images at planetary scale at no monetary cost (Saah et al. 2020; Uddin et al. 2019; Kumar and Mutanga 2018; 
Uddin et al. 2020). GEE maintains a data catalog and processing engine based on the programming languages, JavaScript and Python. The users can build the processing algorithm either in JavaScript or Python which directly access data from GEE's main repository or from its users' asset stored in the GEE cloud space and then apply the algorithm for processing the data.

\subsection{Use of SAR Flood Mapping for Emergency Response in the HKH Region}

In order to deploy rescue and relief operations, disaster management and humanitarian authorities need to know urgently about real-time flood situations. Nevertheless, the traditional flood mapping system has many limitations in terms of providing timely and updated information on the wider flood-prone landscape. In 2008, recognizing that flood maps are necessary for disaster preparedness, ICIMOD started its initiative of SAR image-based flood mapping (Uddin and Shrestha 2011). However, inundation mapping at the level of river basins was only initiated in 2016 when the Koshi River Basin, including India's most flood-prone state, Bihar, was hit by massive floods. So, in order to obtain reliable information on the Koshi River Basin, ICIMOD prepared a district-level flood inundation map for the Bihar State Disaster Management Authority (BSDMA). In this process, images from Advanced Land Observing Satellite - Phased Array L-band Synthetic Aperture Radar (ALOS-PALSAR) were used (Hill 2016; Bhubaneshwar 2016).

This map provided an estimate of the inundated areas, including of agricultural lands, grasslands, barren fields, built-up spaces, and fishponds. The map became useful for the BSDMA in its search-and-rescue operations and in managing relief camps (Bhubaneshwar 2016). However, due to their commercial nature, the data from ALOS-PALSAR were forbidding in terms of the expenses involved in mapping large areas and doing so every year. So, in 2017, for the first time in Bangladesh, rapid flood mapping via Sentinel-1 SAR was initiated which was then continued with when the country faced floods in 2019 (Fig. 10.3). The next section describes the methodology of mapping and the emergency response mechanism that were followed during the recent floods inundation in Bangladesh.

\subsection{Rapid Flood Mapping-Bangladesh, 2019}

For the mapping, 11 Sentinel-1 images were downloaded for Bangladesh directly from the Copernicus Open-Access Hub (https://scihub.copernicus.eu/dhus/\#/home) as the data were available in a few hours from the time of acquisition. These images were in the interferometric-wide (IW) mode, with a minimum of $250-\mathrm{km}$ ground swath in the C-band. The IW-mode data for the country were available as dual polarizations - vertical transmission and the horizontal received (VH) and vertical 
transmission and the vertical received (VV) - at level-1 of the ground range detected (GRD) products. Both polarizations were used in the mapping. Further, the Landsat-8 level-2 image that was acquired on September, 19, 2019 was downloaded from the US Geological Survey (USGS) Global Visualization Viewer (GLOVIS) and used for calibrating the algorithm and validating the flood map.

We used the Sentinel Application Platform (SNAP), an open-access tool available from the Copernicus Hub, for processing the SAR data. A graph builder was developed in SNAP to perform all the steps automatically in a batch-processing mode (Fig. 10.2). Firstly, the images were imported into SNAP. Then, they were radiometrically corrected by image calibration in order to represent the radar backscatter pixel values. After the corrections, the Lee Sigma, window size $7 \times 7$ speckle filter, was applied to reduce the granular noise that usually blurs features in images. Multi-look processing was also carried out to reduce the inherent speckled appearance and to improve the interpretability of the images. Further, terrain correction using the Shuttle Radar Topography Mission (SRTM) 30 m data was performed to remove geometric as well as topographic distortions in the images. The images were then converted from a linear scale to $\mathrm{dB}$ scale for true representation of the radar signals. Finally, a threshold for mapping the flooded areas was calibrated using the Landsat- 8 data. For this analysis, only two major classes-water and non-water-were considered. The flooded area was determined by removing pre-flood waterbodies from the water extent during the flooding time (Jain et al.

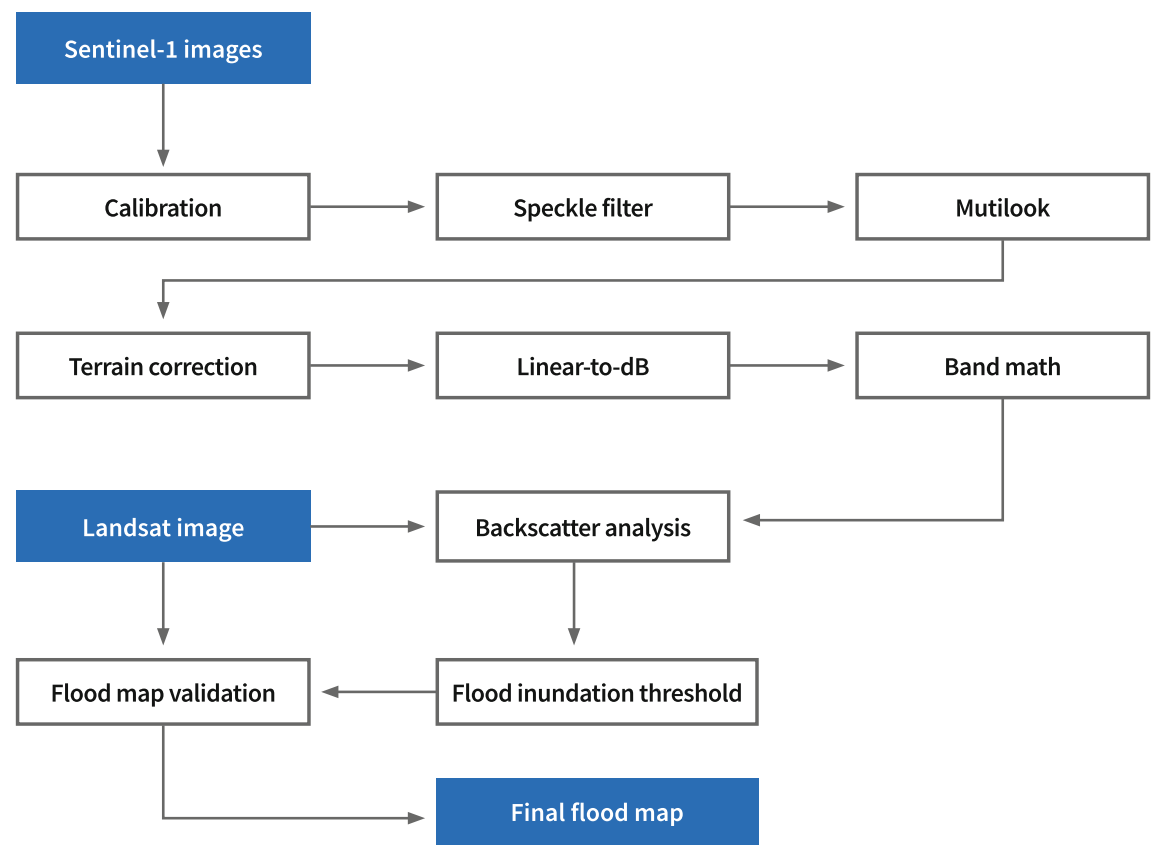

Fig. 10.2 Image processing flow 
2006). The waterbodies that had water before mid-April were considered as perennial water bodies. The April 2019 waterbodies were separated from those of the months of June, July, August, and September, and the map was reclassified to indicate perennial waterbodies, flood areas, and other classes. To have confidence in the analyzed flood maps, we used 500 validation reference points from the Landsat image. The overall accuracy of the flood map in September 2019 as against the reference data was 98 percent. After that, an overlay analysis was carried out to trace the rise in flood and its recession between June and September 2019.

The inundation maps of multiple months were also analyzed for assessing the changes in flood situation during different times of the flooding period. An example of such analysis for the floods in 2017 revealed that while the total flood period spanned from April to August, there were some differences in the inundation patterns in different months. Some of the areas suffered from sustained flooding; in some others, the water had receded; while some areas were newly flooded. Comparatively, in the months of April and June in 2019, an area of 257,729 ha was inundated in both the months; an area of 38,776 ha had recovered from the inundation; and an area of 410,853 ha was newly flooded. At the same time, during the months of June and August in 2019, an area of 532,173 ha was flooded for both the months; some 136,406 ha had recovered from the floods; while an area of 502,927 ha was newly inundated. The 2019 rapid flood mapping exercise for entire Bangladesh went on to produce inundation maps for the months of June, July, August, and September (Fig. 10.3).

\subsection{Dissemination and Outcome}

One of the best outcomes of the flood mapping exercise was the rapid generation of inundation maps and sharing of that information with the relevant people using different communication channels. In addition to generating digital maps, the geo-referenced inundation data layers were also disseminated to a wider group of users through an information portal to enable further analysis by the users (WFP 2017). A web-based portal was also created for flood map visualization with overlay option showing different administrative boundaries. Such flood-associated information, maps, and data were downloadable to support further analysis by the users (Fig. 10.4). Digital maps of A1-size were also disseminated to disaster management committees for printing and using offline. The rapid inundation maps were widely used for responses and were appreciated by humanitarian agencies (Fig. 10.4). 


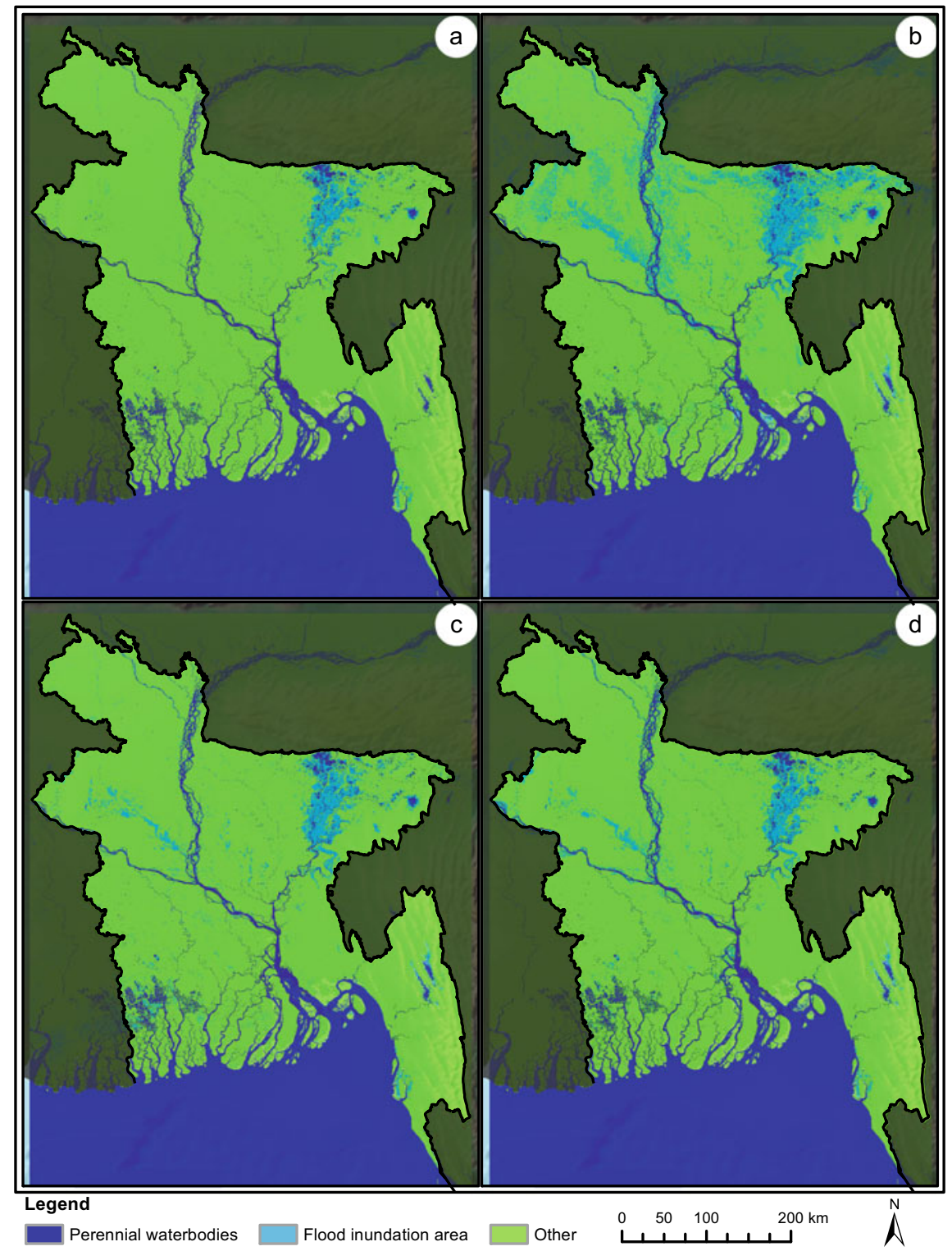

Fig. 10.3 Sentinel-1-based flood inundation map of Bangladesh for the months of: a June; b July; c August; and d September 2019 


\title{
$\equiv$ SERVIR HOMOUKUSH
}

$I C I M O D \equiv$

Taking stock of the damage: Mapping the impact of the 2019 Bangladesh floods using satellite imagery

\begin{abstract}
23 Jul 2019
Millions have been displaced $\%$ and more than 130 people killed $\%$ in Bangladesh, India, and Nepal as the onset of the 2019 South Asian monsoon triggers floods and landslides across South Asia. The floods in Bangladesh are possibly the worst in recent years 9 . In Bangladesh, the Jamuna River broke through an embankment on the night of 17 July 2019 , inundating at least 40 villages and displacing more than 200,000 peoples. Official estimates report 1 that over 100,900 ha of crops have been damaged and livestock fisheries, and poultry have been severely impacted by the floods in Bangladesh.
\end{abstract}

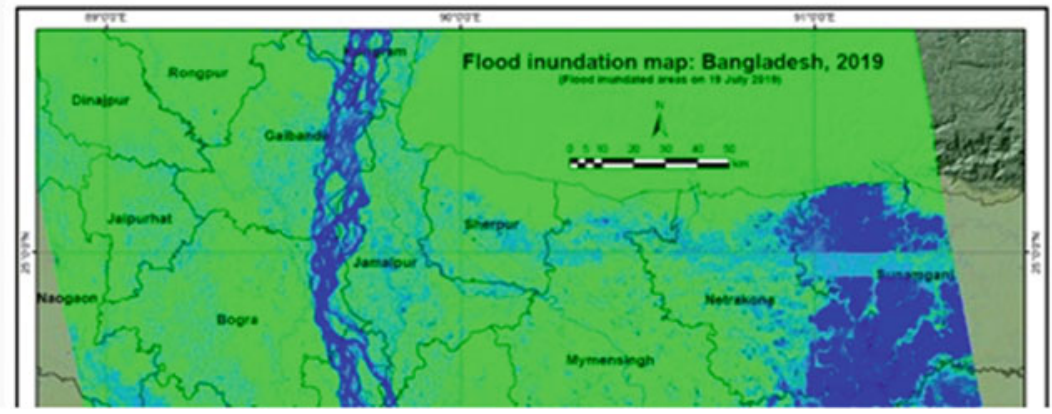

Fig. 10.4 News on flood mapping

\subsection{Conclusion and Way Forward}

This chapter has described the use of SAR satellite data and the open access software platform for flood mapping and has demonstrated a robust method to prepare NRT flood maps for rapid response missions. The application of the method for the Bangladesh floods of 2019 has been described as an example. The mapping method also achieved high classification accuracy. The flood maps show the high potential of EO and geospatial technology to analyze and provide the necessary support for prompt and effective decisions on flood disaster management to the authorities. In the wake of constant weather constraints during the flooding time, the example shows the rich potential of freely available Sentinel-1 SAR-based solutions to produce detailed mapping with high accuracy. The frequent occurrence of natural flood disasters is common in the HKH region, and it needs efficient tools for flood mapping in order to support damage assessment, emergency response, and disaster management.

However, desktop-based computer analysis limits the quick processing of large-scale mapping using Sentinel-1 images due to the file size. If all the Sentinel-1 data become available on an NRT basis in GEE, then the processing will be much faster to meet user needs during floods. The method can also be adapted easily in 
the earth engine platform. In the case of Bangladesh, the operational mapping applications have produced a flood map with the best precision at a national scale. Nevertheless, there were some issues with the flood maps due to existence of floating vegetation. The SAR Sentinel-1 images sometimes showed paddy fields as flooded areas while that was not the case. In those cases, local knowledge could play a significant role.

\section{References}

Ajmar A, Boccardo P, Broglia M, Kucera J, Giulio-Tonolo F, Wania A (2017) Response to flood events: the role of satellite-based emergency mapping and the experience of the copernicus emergency management service. Flood Damage Surv Assess New Insights Res Pract 228:213

Amarnath G, Rajah A (2016) An evaluation of flood inundation mapping from MODIS and ALOS satellites for Pakistan. Geomatics, Nat Hazards Risk 7(5):1526-1537. https://doi.org/10.1080/ 19475705.2015.1084953

Bhubaneshwar (2016) Most flood-prone state Bihar aided by new satellite mapping. Financial Express

Cigna F, Xie H (2020) Imaging floods and glacier geohazards with remote sensing. Multidisciplinary Digital Publishing Institute, Switzerland

Dewan TH (2015) Societal impacts and vulnerability to floods in Bangladesh and Nepal. Weather Clim Extremes 7:36-42

FFWC (2020) Definitions-the floods in Bangladesh. Flood Forecasting and Warning Centre, Bangladesh Water Development Board (BWDB). Accessed 01 Sept 2020

Hill E (2016) India-Palsar remote sensing enables accurate flood-mapping of Bihar State. Flood List

Jain SK, Saraf AK, Goswami A, Ahmad T (2006) Flood inundation mapping using NOAA AVHRR data. Water Resour Manage 20(6):949-959

Kumar L, Mutanga O (2018) Google Earth Engine applications since inception: usage, trends, and potential. Remote Sens 10(10):1509

Longépé N, Rakwatin P, Isoguchi O, Shimada M, Uryu Y, Yulianto K (2011) Assessment of ALOS PALSAR $50 \mathrm{~m}$ ortho rectified FBD data for regional land cover classification by support vector machines. IEEE Trans Geosci Remote Sens 49(6):2135-2150

Manjusree P, Kumar LP, Bhatt CM, Rao GS, Bhanumurthy V (2012) Optimization of threshold ranges for rapid flood inundation mapping by evaluating backscatter profiles of high incidence angle SAR images. Int J Disaster Risk Sci 3(2):113-122

Ohki M, Watanabe M, Natsuaki R, Motohka T, Nagai H, Tadono T, Suzuki S, Ishii K, Itoh T, Yamanokuchi T (2016) Flood area detection using ALOS-2 PALSAR-2 data for the 2015 heavy rainfall disaster in the Kanto and Tohoku Area, Japan. J Remote Sens Soc Japan 36 (4):348-359. https://doi.org/10.11440/rssj.36.348

Ozaki M (2016) Disaster risk financing in Bangladesh. Working Paper Series No. 46, September 2016. ADB South Asia. http://dx.doi.org/10.2139/ssrn.2941319

Rasid H, Pramanik M (1993) Areal extent of the 1988 flood in Bangladesh: how much did the satellite imagery show? Nat Hazards 8(2):189-200

Saah D, Tenneson K, Poortinga A, Nguyen Q, Chishtie F, San Aung K, Markert KN, Clinton N, Anderson ER, Cutter P (2020) Primitives as building blocks for constructing land cover maps. Int J Appl Earth Obs Geoinf 85:101979

Shimada M, Itoh T, Motooka T, Watanabe M, Shiraishi T, Thapa R, Lucas R (2014) New global forest/non-forest maps from ALOS PALSAR data (2007-2010). Remote Sens Environ 155:13-31 
Uddin K, Gurung DR, Giriraj A, Shrestha B (2013) Application of Remote Sensing and GIS for flood hazard management: a case study from Sindh Province, Pakistan. Am J Geogr Inf Syst 2 (1):1-5. https://doi.org/10.5923/j.ajgis.20130201.01

Uddin K, Khanal N, Chaudhary S, Maharjan S, Thapa RB (2020) Coastal morphological changes: Assessing long-term ecological transformations across the northern Bay of Bengal. Environ Challenges 1:100001

Uddin K, Matin MA, Meyer FJ (2019) Operational flood mapping using multi-temporal sentinel-1 SAR images: a case study from Bangladesh. Remote Sens 11(13):1581

Uddin K, Shrestha B (2011) Assessing flood and flood damage using remote sensing: a case study from Sunsari, Nepal. Paper presented at the $4^{\text {th }}$ international conference on water and flood management, Dhaka

Voormansik K, Praks J, Antropov O, Jagomagi J, Zalite K (2014) Flood mapping with TerraSAR-X in forested regions in Estonia. IEEE J Sel Topics Appl Earth Observations Remote Sens 7(2):562-577

WFP (2017) Terai flood 72 hour assessment [Version 1], August 2017. WFP, Kathmandu

Open Access This chapter is licensed under the terms of the Creative Commons Attribution 4.0 International License (http://creativecommons.org/licenses/by/4.0/), which permits use, sharing, adaptation, distribution and reproduction in any medium or format, as long as you give appropriate credit to the original author(s) and the source, provide a link to the Creative Commons license and indicate if changes were made.

The images or other third party material in this chapter are included in the chapter's Creative Commons license, unless indicated otherwise in a credit line to the material. If material is not included in the chapter's Creative Commons license and your intended use is not permitted by statutory regulation or exceeds the permitted use, you will need to obtain permission directly from the copyright holder.

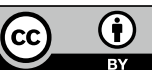

